\title{
Early Korea: Re-thinking Boundaries and Identities
}

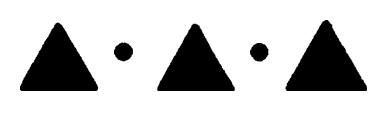

Jack DAvey and Dennis LeE

\section{INTRODUCTION}

The LAST Ten years haVe BeEn PRODUCtive fOR Korean archaeology and early Korean historical studies. A mature practice of field archaeology in Korea is producing more excellent data every year. There has been a flurry of new scholarship both within and outside Korea, with many studies rethinking and re-evaluating commonly held assumptions and beliefs regarding the interpretation of material culture, and significantly, much more of these data and associated research are available in English than ever before. Of particular note here are the Early Korea volumes produced by the Early Korea Project at Harvard University and the 2015 (vol. 54, no. 1) special issue of Asian Perspectives. These sources have provided excellent introductions and surveys of major periods and issues within early Korean archaeology and history.

The current special issue is the result of a conference on "Interdisciplinary Approaches to Early Korea" held at University of California, Berkeley on 27 April 2017. The conference brought together scholars working on material from the Korean peninsula who blend history and archaeology in interesting ways or eschew traditional approaches entirely. The goal of this conference and this special issue is not to offer another "state of the field" overview, but to highlight the diverse and innovative approaches of early career scholars working outside of Korean academia. As a result, this issue is not strictly archaeological, historical, or focused on any one time period. The articles draw on literary studies, archaeometric techniques, and critiques of mainstream historiography in addition to more traditional historical and archaeological methodologies. It might be better thought of as a showcase of scholarship ranging chronologically from the Mumun, Iron Age, and Proto-Three Kingdoms to the Three Kingdoms periods of Korea, all under the interdisciplinary heading of "Early Korea." Although the contributors cover a variety of different topics and time periods, several coherent themes emerge from their collective work, discussed below. We hope that by providing a frame through which to think through these broader issues, scholars working elsewhere in East Asia will find value in these articles.

Jack Davey is an Adjunct Professor at George Washington University. Dennis Lee is an Assistant Professor at Yonsei University. 


\section{Deconstructing Geonationalism and Redrawing Boundaries}

Investigation of the colonial origins and nationalistic biases that underpin much of the foundational work in Korean archaeology and history has been undertaken both inside and outside of Korean academia. While Hyung Il Pai's (2000) study remains one of the most significant critiques of such biases published in English, it has recently been joined by other sophisticated works by Stella Xu (2016) and Yi Sŏngju (2017). Rather than repeating their criticisms, several of the contributors published in this special issue highlight equally pervasive aspects of geonationalism inherent to Korean, Japanese, and Western scholarship of early Korea (Lee 2014). They examine hegemonic textual interpretations and commonly understood regionalisms that presuppose cultural unity within the peninsula and thus constrain our understanding of local cultural dynamics. This is one of a number of new directions being pursued by archaeologists and historians in Korea (for further reflections on archaeological practice, consult recent issues of the premier Korean archaeological journal, Han'guk Kogo Hakpo 韓國考古學報).

Dennis Lee challenges the traditional and textually-derived understanding of Paekche's control of the southern peninsula in the fourth century. He redraws Paekche's southern boundaries through a critical appraisal of the problematic Jingū narrative of the Nihon shoki. Rather than following the "Yamato" or "Paekche" invasion interpretations of previous scholars, Lee suggests that a close reading of the Jing $\bar{u}$ passage itself entirely refutes the idea of an invasion. Furthermore, the material culture of the supposedly conquered Yŏngsan River Basin region actually points to a culturally independent group largely absent from the historical record.

Similarly, Hari Blackmore deconstructs the Chungdo cultural sphere idea that has pervaded scholarship of the Iron Age archaeology of Central Korea. He argues that the monolithic archaeological cultures usually assigned to Mahan and Ye do not reflect the true complexity of the material in both regions and need to be reevaluated.

Jack Davey, Lauren Glover, and J. M. Kenoyer push back against assumptions of "Korea" as a unit of analysis by situating the peninsula in a larger Asian context. Davey argues that complex material indicators of cultural interaction in southern peninsular Iron Age tombs (i.e., bronze mirrors and decorated iron staff-heads) shed light on the arbitrariness and anachronisms inherent to assumptions of unitary "Korean" and "Chinese" cultures.

Through their analysis of carnelian beads in Proto-Three Kingdoms and Three Kingdoms tombs, Glover and Kenoyer situate Korea in its broadest possible context. This breaks the region out of the insular focus it is often given in material studies and has interesting implications for peninsular contacts with Southeast Asia.

Finally, Rachel Lee explores boundaries and space from a completely different perspective by focusing on an aspect of Mumun period archaeology almost completely ignored in existing scholarship: the spatial expression of gender within households. Her conclusion, that gender roles seem to have been relatively fluid at the level of the household, also pushes back on gender biases and assumptions still pervasive in South Korea today.

\section{Text, Archaeology, and Materiality}

Instead of focusing on historical polities or restricted sets of diagnostic artifacts and features, several contributors offer alternative material and textual engagements. The 
models and methodologies proposed by the authors in this issue have a broad relevance for scholars thinking through the same issues elsewhere in Asia, where a lack of critical reflection on textual dominance and the heuristic utility of static material cultures remain entrenched.

Mark Byington demonstrates how an integrative approach to textual and material culture can move beyond the limitations of both sources to enrich our understanding of early Koguryo history and the complexities of this kingdom's mortuary practices. An intriguing implication of his study is the degree to which placement relative to other tombs, line-of-sight, and the early Koguryŏ capital determined the location of royal burials.

By contrast, Dennis Lee and Jack Davey assess the archaeological and historical records completely separately. For Lee, considering the material culture of the southern coast independent of historical sources frees our interpretation of these groups from the "Paekche," "Yamato," and "Mahan" baggage they have accrued over the years. Davey suggests that by not simply assuming that the material culture of the southeastern Iron Age conforms to Chinhan and Pyŏnhan cultures, we can begin to explore the complex sociocultural diversity of the region as expressed through mortuary practices.

Marjorie Burge's study of Sabi period Paekche mokkan (inscribed wooden tablets) also takes into account the textual and material dimensions of these fascinating objects. Her analysis, which combines a sophisticated interpretation of the content as well as a consideration of the material form of the tablets, forces us to rethink the process of literacy acquisition in the Three Kingdoms period. The ephemeral nature of these objects, she argues, made them ideal tools for learning and experimenting with established literary conventions.

\section{Korea as a Laboratory}

Beyond these methodological integrations, some of the contributors make the case for the Korean peninsula as a productive laboratory for new and novel archaeological techniques and use it as a case study to join larger theoretical conversations.

Rachel Lee demonstrates the potential for the Mumun period to contribute to a broader reassessment and engagement with gender in archaeology. But more than simply calling for a change in perspective, she demonstrates where and how we might look for gender dynamics through a quantitative assessment of activity patterns within households and dwelling structure.

Rory Walsh, Gyoung-Ah Lee, and Young-Cheol Lee take a similarly nuanced approach to Mahan and Paekche pottery. In addition to providing new knowledge about Iron Age ceramic sourcing and production gained by their use of INAA, the authors situate their insights within a larger socio-political context. More than uncovering the connections in production between two major Mahan and Paekche sites, they suggest that these similarities point to a larger and more fundamental similarity in the political organization of these groups. This approach is echoed in Glover and Kenoyer's study, which invites us to think through concepts of value through its reappraisal of beads in a mortuary context.

\section{Early Polities}

Many of the articles touch on the topic of the formation of the first complex polities on the peninsula during the late Mumun period and Iron Age. Several articles focus on 
Mahan, a cultural designation for a number of polities or statelets that first appeared in Chinese texts of the third century but have been conventionally assigned to the archaeology of central and southwestern Korea. What is significant about Mahan is how it complicates not only our perceptions of "Korean" and regional archaeological cultures in the peninsula, but also our ideas of social evolution, complexity, and state formation more generally.

Dennis Lee and Blackmore touch on the ambiguity of Mahan's territorial extent, its cultural homogeneity, and its relationship to Paekche and other Iron Age groups. The supposed northern and southern extents of Mahan territory do not conform to any convenient textual description of Mahan groups and the material culture of specific areas such as the Yŏngsan River region seems wholly unique, especially with regard to mortuary practices. Blackmore also argues that the northern extent of Mahan culture and the area where Paekche supposedly emerged - that is, the Han River regionactually has more in common archaeologically with the material culture of the Central Region of Korea (the Imjin River region and Kangwŏn Province). If Paekche was indeed originally one of the fifty statelets that made up Mahan culture, how are we to account for this archaeological distinction?

The implications of Blackmore's study contrast interestingly with Walsh, Lee, and Lee's article, which also touches on Mahan's relationship to Paekche as well as ongoing debates surrounding Mahan's development towards state-level complexity. Many other archaeologists have emphasized the distinctiveness of Mahan culture, but their analysis somewhat pushes back on the idea that Mahan's developmental trajectory was wholly different from Paekche's. They suggest that differences in pottery production between Hansong Paekche and Mahan were distinctions of degree, but that the two were fundamentally similar in organization and distribution. Mahan and Paekche may have shared more social, political, and technological links than we might think.

We hope this special issue showcases the potential and dynamism of Early Korean studies. In recent years, contemporary nationalism in South Korea has had a detrimental impact on the academic freedom and sustainability of research on the ancient culture of the peninsula. Collectively, these articles aim to break down limiting categories and mindsets and present interesting case studies relevant to East Asia and the world.

\section{NOTES ON ROMANIZATION}

The Romanization for this special issue has been standardized to McCune-Reischauer. South Korea, however, uses a competing system, commonly referred to as Revised Romanization, in its museums, research institutes, and archaeological site reports. This creates multiple spellings for place names and geographical features, political divisions and historical polities, archaeological terms, and so on. This has created a fierce debate among scholars working on Korea about which system to use.

The Romanization debate is beyond the scope of this issue, but we have decided to use McCune-Reischauer because it harmonizes with previously published works in English such as the Early Korea volumes and is the standard used by the Library of Congress for Korean studies. The ALA-LC rules of McCune-Reischauer are also currently more completely developed than the Revised Romanization rules. However, we recognize that some of the contributors have published exclusively within the Revised Romanization system, so as a compromise where requested, we have included the Revised Romanization (RR) in addition to the McCune-Reischauer orthography. 


\section{ACKNOWLEDGMENTS}

We would like to thank the Center for Korean Studies at UC Berkeley for funding and hosting the Early Korea workshop that led to this issue. In particular, the program chair Laura Nelson and program director Stephanie Kim were instrumental in making the workshop possible. The comments of workshop discussants Jonathan Best, Gyoung-Ah Lee, and Martin Bale, as well as keynote speaker Stella Xu, were invaluable in helping contributors refine and improve their articles. We are also grateful to the Editors of Asian Perspectives, Rowan Flad and Mike Carson. Finally, we would like to specially acknowledge Martin Bale, who passed away during the preparation of this issue. Dr. Bale was not only essential to the creation of this volume but also a leading scholar in Early Korean Studies. Many of the contributors in this volume owe a considerable debt to his tireless guidance and friendship. We felt it only appropriate to dedicate this special issue to him.

\section{REFERENCES CITED}

Lee, Dennis Hyun-Seung

2014 Keyhole-Shaped Tombs and Unspoken Frontiers: Exploring the Borderlands of Early KoreanJapanese Relations in the 5th-6th Centuries. Ph.D. diss. University of California, Los Angeles, Los Angeles.

PAI, Hyung IL

2000 Constructing "Korean" Origins: A Critical Review of Archaeology, Historiography, and Racial Myth in Korean State-Formation Theories. Cambridge, MA: Harvard University Press.

$\mathrm{Xu}, \mathrm{S}$ Tella

2016 Reconstructing Ancient Korean History: The Formation of Korean-ness in the Shadow of History. Lanham: Lexington Books.

YI SŎNGJU 李盛周

2017 Han'guk kogohak ŭi kiwŏn ron kwa kyet'ong ron 韓國考古學의 起源論과 系統論 [Studies on cultural origin and transmission in Korean archaeology]. Han'guk Kogo Hakpo 韓國考 古學報 102:128-163. 